\title{
Merging the Sol-Gel Technique with the Pulsed Microplasma Cluster Source Deposition to Improve Control over the Memristive Response of $\mathrm{TiO}_{2}$ Thin Films
}

\author{
Valentina Prusakova ${ }^{1}$, Giovanni Giusti ${ }^{2}$, Cristian Collini ${ }^{3}$, Giancarlo Pepponi ${ }^{3}{ }^{(\mathbb{D},}$, Mario Barozzi ${ }^{3}$, \\ Leandro Lorenzelli ${ }^{3}$, Salvatore Iannotta ${ }^{4}$, Roberto Verucchi ${ }^{2, *}$ (i) and Sandra Dirè ${ }^{1}$ \\ 1 Department of Industrial Engineering, University of Trento, Via Sommarive 9, 38123 Trento, Italy; \\ sleepymadhatter@gmail.com (V.P.); sandra.dire@unitn.it (S.D.) \\ 2 IMEM-CNR Institute of Materials for Electronics and Magnetism, Trento Unit c/o Fondazione Bruno Kessler, \\ Via alla Cascata 56/C, Povo, 38123 Trento, Italy; giovanni.giusti86@gmail.com \\ 3 Foundation Bruno Kessler-Sensors and Devices (FBK-SD), Via Sommarive 18, 38123 Trento, Italy; \\ ccollini@fbk.eu (C.C.); pepponi@fbk.eu (G.P.); barozzi@fbk.eu (M.B.); lorenzel@fbk.eu (L.L.) \\ 4 IMEM-CNR, Institute of Materials for Electronics and Magnetism, Parco Area delle Scienze 37/A, \\ 43124 Parma, Italy; salvatore.iannotta@cnr.it \\ * Correspondence: roberto.verucchi@cnr.it; Tel.: +39-0461-314-825
}

Citation: Prusakova, V.; Giusti, G.; Collini, C.; Pepponi, G.; Barozzi, M.; Lorenzelli, L.; Iannotta, S.; Verucchi, R.; Dirè, S. Merging the Sol-Gel Technique with the Pulsed Microplasma Cluster Source Deposition to Improve Control over the Memristive Response of $\mathrm{TiO}_{2}$ Thin Films. Coatings 2021, 11, 348. https://doi.org/10.3390/coatings11030348

Received: 4 February 2021

Accepted: 16 March 2021

Published: 18 March 2021

Publisher's Note: MDPI stays neutra with regard to jurisdictional claims in published maps and institutional affiliations.

Copyright: (c) 2021 by the authors. Licensee MDPI, Basel, Switzerland. This article is an open access article distributed under the terms and conditions of the Creative Commons Attribution (CC BY) license (https:// creativecommons.org/licenses/by/ $4.0 /)$.
Abstract: Metal oxide thin films show promising resistive switching properties, making them materials of reference for the development of memristive devices. $\mathrm{TiO}_{2}$ is probably one of the most studied materials and is being synthesized using various techniques, each of them having specific optimizable characteristics. In this paper, we report on an innovative approach by combining the sol-gel and the pulsed microplasma cluster source (PMCS) methods, exploiting the low temperature and low cost of the former process and precise control over nanocristallinity of the latter. We show that this approach overcomes the reported limitations that each technique shows in fabricating memristive devices when independently used. A side-by-side comparison of the $\mathrm{TiO}_{2}$ thin films produced by the PMCS, sol-gel, and PMCS/sol-gel hybrid methods (HM) demonstrates an improvement of the memristive properties and a reduction of the electrical shorts in the $\mathrm{TiO}_{2}$ based devices.

Keywords: memristor; titanium dioxide; sol-gel; PMCS; thin films

\section{Introduction}

Ever since the discovery of a $\mathrm{TiO}_{2}$-based memristor [1], metal oxide thin films, such as $\mathrm{TiO}_{2}, \mathrm{HfO}_{2}, \mathrm{ZnO}, \mathrm{Ta}_{2} \mathrm{O}_{5}$, have been extensively studied as promising building blocks for electronic devices [2-5]. The switch between low and high resistive states results in a bipolar hysteresis current/voltage IV loop, pinched at $0 \mathrm{~V}$ and $0 \mathrm{~A}$ [6]. The resistive switch mechanism in $\mathrm{TiO}_{2}$ based devices (as well as other metal oxides) relies on forming a nanofilament that contains oxygen vacancies responsible for a low resistive state. To develop the electrical devices, a detailed insight in the resistive switch is still of demand, and several theoretical studies have been conducted [7-9]. Driven by this interest, various thin films with a typical thickness of around tens of $\mathrm{nm}$ were fabricated by methods where synthesis is achieved by chemical reactions with specific precursors or exploiting direct physical deposition of material in a vacuum. In particular, $\mathrm{TiO}_{2}$ thin films were successfully fabricated by atomic layer deposition (ALD) [10,11], reactive magnetron [12], ion beam [13], radio frequency (R.F.) sputtering [14] and laser ablation [15]. In addition to these methods, $\mathrm{TiO}_{2}$ thin films were fabricated by the sol-gel approach [16] and metal organic chemical vapor deposition [17].

Each method has its own limitations ranging from the process costs, temperature conditions, stoichiometry control, uniformity, and deposition area. For example, the sol-gel technique is a low-temperature, low-cost process that may produce smooth and uniform 
films. Nevertheless, even though the stoichiometry control of sol-gel derived materials is possible by doping or processing the films in a selected atmosphere, precise control over oxygen atomic percentage is hard to achieve. On the other hand, employing the pulsed microplasma cluster source (PMCS) technique it is possible to produce nanocrystalline $\mathrm{TiO}_{2}$ thin films at room temperature $[18,19]$, with a precise control on oxide stoichiometry, consistent biocompatibility with neuronal tissues and satisfactory memristive response [20]. The typical high porosity of PMCS films is ideal for sensing applications [21], but could lead to short circuits in electronic devices when a top electrode (TE) coating is required [11]. We have already extensively studied the oxide films developed by the PMCS and the solgel approaches independently, optimizing the respective process parameters to develop reliable memristive switching devices.

In this work, we propose merging the PMCS and the sol-gel techniques to profit from the methods' advantages and overcome the specific limitations. We present a proof of concept and feasibility study showing that this hybrid method is a versatile tool for developing the target $\mathrm{TiO}_{2}$ thin films with a memristive response. A side-by-side comparison of the $\mathrm{TiO}_{2}$ thin films produced by the PMCS, the sol-gel, and the PMCS/sol-gel hybrid method (HM) shows that the new approach leads to materials with memristive switching, a large reduction of electrical shorts probability, and improved device electrical performances.

\section{Materials and Methods}

We developed all $\mathrm{TiO}_{2}$ films on a $\mathrm{SiO}_{2} / \mathrm{Ti} / \mathrm{Pt}$ bottom electrode (BE) that was fabricated as reported previously [16]. Before all the depositions, the $\mathrm{SiO}_{2} / \mathrm{Ti} / \mathrm{Pt}$ electrodes $\left(1.5 \times 1.5 \mathrm{~cm}^{2}\right)$ were cleaned with acetone, rinsed with isopropanol, DI water, and dried in a stream of nitrogen. In addition to cleaning, oxygen downstream plasma etching of electrodes was performed to produce the sol-gel-derived $\mathrm{TiO}_{2} \mathrm{~S}$ samples.

The details of the titania sol preparation and a spin coating recipe were published previously [16]. The two-layered sol-gel derived $\mathrm{TiO}_{2}$ thin films, $\mathrm{TiO}_{2} \mathrm{~S}$, were used as one of the two models to investigate the samples prepared by the HM.

Analogously, we used the PMCS method to prepare $\mathrm{TiO}_{2} \mathrm{P}$ model samples by a previously reported procedure [20]. Briefly, the deposition process is based on the ablation of a titanium rod by a pulsed plasma, created by the ionization of a pulsed high pressure gas ( $30 \mathrm{bar}$ ) triggered by an electric discharge at $1.2 \mathrm{kV}$. The mixture of clusters and inert gas is extracted in vacuum through a nozzle to form a seeded supersonic molecular beam. The $\mathrm{TiO}_{2}$ films with different thicknesses were deposited at room temperature using $\mathrm{O}_{2} / \mathrm{He}$ gas mixture percentages of $0.1 / 99.9 \%$. Typical pulsed gas electro-valve opening time and frequency were $700 \mu \mathrm{s}$ and $4 \mathrm{~Hz}$ respectively, while the delay between the electric discharge and valve opening was set at $700 \mu \mathrm{s}$.

The $\mathrm{TiO}_{2} \mathrm{H}$ sample fabrication started with the deposition of a $\mathrm{TiO}_{2}$ layer by the PMCS method onto the clean electrodes. After that, spin coating of the titania sol on $\mathrm{TiO}_{2}$ layer was performed in a clean room (class 100-1000 equipped for MEMS technology). The fresh sol was transferred into a glass syringe and filtered through Millipore Millex-FG Hydrophobic PTFE (Teflon) $0.2 \mathrm{~mm}$ before the deposition on the $\mathrm{TiO}_{2}$ layer. The filtered sol was spin-coated with the following protocol: $1300 \mathrm{rpm}$ for $2 \mathrm{~s}(0 \rightarrow 1300: 2 \mathrm{~s})$, followed by $2000 \mathrm{rpm}$ for $2 \mathrm{~s}(1300 \rightarrow 2000: 2 \mathrm{~s})$, and finally with $3000 \mathrm{rpm}$ for $49 \mathrm{~s}(2000 \rightarrow 3000: 1 \mathrm{~s})$. The resulting $\mathrm{TiO}_{2} \mathrm{H}$ samples were heat treated for $1 \mathrm{~h}$ at $150^{\circ} \mathrm{C}$ and annealed in air atmosphere for $1 \mathrm{~h}$ at $400{ }^{\circ} \mathrm{C}$, following optimized conditions published elsewhere $[5,16]$.

Platinum (270-300 $\mu \mathrm{m}$ in diameter, $40-50 \mathrm{~nm}$ thick) circular shaped electrodes were hence deposited by the electron beam evaporation onto $\mathrm{TiO}_{2} \mathrm{~S}, \mathrm{TiO}_{2} \mathrm{P}$, and $\mathrm{TiO}_{2} \mathrm{H}$ using a shadow mask with dish-shaped patterns. The Pt films were evaporated from a Pt rod ( $99.99 \%$ purity, supplied by Umicore, Pforzheim, Germany) in a vacuum chamber using an e-beam evaporator EBX-16C (Ulvac, Methuen, MA, USA). The pressure during deposition was adjusted to $2.4 \times 10^{-7}$ torr with the evaporation rate of $0.1 \mathrm{~nm} \mathrm{~min}{ }^{-1}$.

The FE-SEM characterization was performed by SEM (JSM-7401 FIB-SEM, JEOL, Tokio, Japan) with accelerating voltage of $3 \div 5 \mathrm{KV}, 10^{\circ}$ sample tilt, working distance of $5 \div 6 \mathrm{~mm}$ 
and a secondary electrons signal. The surface roughness was evaluated from SEM images. Optical images were obtained by a monocular inspection microscope SKU:H800 (AmScope) coupled with a MU800 digital camera (AmScope). The thickness measurements were carried out by the profilometry technique using a TENCOR P6 mechanical profilometer (Milpitas, CA, USA).

X-ray photoelectron spectroscopy (XPS) was carried out in an ultra-high-vacuum (UHV) system (custom made), equipped with a non-monochromatized X-ray source (Mg $\mathrm{K} \alpha$ photon at $1253.6 \mathrm{eV}$ ) and a VSW HA100 hemispherical analyzer, with a total energy resolution of $0.86 \mathrm{eV}$ [22]. The binding energy (BE) scale of XPS spectra was calibrated by using the $\mathrm{Au} 4 \mathrm{f}$ peak at $84.0 \mathrm{eV}$ as a reference. The core level analysis has been performed by Voigt line-shape deconvolution after background subtraction of a Shirley function. Stoichiometry was evaluated using sensitivity factors corrected by analyzer electron transmission.

Current-controlled electrical testing was accomplished with NI PXIe-1073 chassis connected to a PC through a PCI-express card and controlled by a software (v. 2014) user interface developed within the Labview environment. The chassis was equipped with a NI-PXIe-4139 source measure unit capable of current or voltage controlled supply and measurement. The I-V curves were recorded in an ambient atmosphere at RT. The BE was the $\mathrm{SiO}_{2} / \mathrm{Ti} / \mathrm{Pt}$ substrate, while the deposited Pt discs were the TE.

\section{Results}

The novel hybrid deposition method consists of two sequential procedures: PMCS followed by a spin coating deposition of the titania sol. We previously extensively studied and reported each of these two optimized procedures for the development of $\mathrm{TiO}_{2}$ thin films with a memristive behavior $[16,18-20,23]$. The first oxide layer deposited on a $\mathrm{SiO}_{2} / \mathrm{Ti} / \mathrm{Pt}$ electrode by the PMCS method is about $30 \mathrm{~nm}$ thick with a $2.8 \pm 0.1 \mathrm{~nm}$ roughness (estimated from SEM images, not shown, Table 1). The PMCS-derived $\mathrm{TiO}_{2}$ films display large roughness, as expected. In our previous studies, for the sol-gel derived oxide films, we observed that the two-layered smooth and dense films displayed a reduced number of short circuits due to the elimination of surface defects upon introducing the second

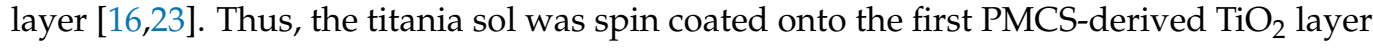
to improve homogeneity, roughness, and porosity (Figure 1).

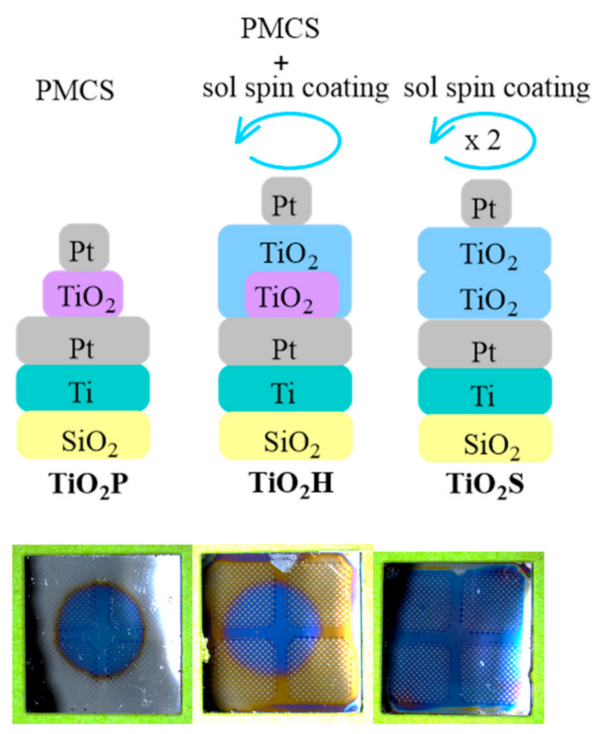

Figure 1. A schematic representation of the three memristive cells (top) with the $\mathrm{TiO}_{2}$ layers produced by (from left to right) the pulsed microplasma cluster source, $\mathrm{PMCS}\left(\mathrm{TiO}_{2} \mathrm{P}\right)$, the hybrid $\left(\mathrm{TiO}_{2} \mathrm{H}\right)$, and the sol-gel $\left(\mathrm{TiO}_{2} \mathrm{~S}\right)$ methods, together with the images of the different type of devices (bottom). 
Table 1. Properties of the three types of $\mathrm{TiO}_{2}$ thin films. In the case of $\mathrm{TiO}_{2} \mathrm{H}$, we also report properties of the two single layers from PMCS and sol-gel methods composing the film.

\begin{tabular}{ccc}
\hline $\mathrm{TiO}_{\mathbf{2}}$ Thin Film & Thickness $(\mathbf{n m})$ & Surface Roughness \\
\hline $\mathrm{TiO}_{2} \mathrm{P}$ & 50 & $2.9 \pm 0.1 \mathrm{~nm}$ \\
$\mathrm{TiO}_{2} \mathrm{~S}$ & 52 & $0.7 \pm 0.1 \mathrm{~nm}$ \\
$\mathrm{TiO}_{2}(\mathrm{PMCS})$ & $\sim 30$ & $2.8 \pm 0.1 \mathrm{~nm}$ \\
$\mathrm{TiO}_{2}($ sol-gel, 1 layer) & 30 & - \\
$\mathrm{TiO}_{2} \mathrm{H}$ & 50.5 & $1.1 \pm 0.1 \mathrm{~nm}$ \\
\hline
\end{tabular}

A single sol-gel derived $\mathrm{TiO}_{2}$ layer, with a typical thickness of about $30 \mathrm{~nm}$ was deposited on the $\mathrm{PMCS}_{\mathrm{TiO}}$ film. After curing, the $\mathrm{TiO}_{2} \mathrm{H}$ film has a total thickness of $50.5 \mathrm{~nm}$ with a roughness of $1.1 \pm 0.1 \mathrm{~nm}$ (Table 1 ).

To investigate the $\mathrm{TiO}_{2} \mathrm{H}$ electrical properties, two $\mathrm{TiO}_{2}$ based devices were fabricated exclusively by the PMCS $\left(\mathrm{TiO}_{2} \mathrm{P}\right)$ and by the sol-gel method $\left(\mathrm{TiO}_{2} \mathrm{~S}\right)$ to serve as models (Figure 1). The $\mathrm{TiO}_{2} \mathrm{P}$ set of samples was prepared by the PMCS method under the same conditions used for $\mathrm{TiO}_{2} \mathrm{H}$, yielding nanocrystalline $\mathrm{TiO}_{2}$ anatase thin films $[18,19]$ of about $50 \mathrm{~nm}$ with a roughness of $2.9 \pm 0.1 \mathrm{~nm}$ (Table 1, Figure 1). The sol-gel derived double-layered $\mathrm{TiO}_{2} \mathrm{~S}$ thin films have a thickness of $52 \mathrm{~nm}$ and roughness of $0.7 \pm 0.1 \mathrm{~nm}$ and consist predominantly of an anatase phase (Table 1, Figure 1) [23]. The thickness of the $\mathrm{TiO}_{2}$ layers is a crucial parameter for the memristive switching response; thus, $\mathrm{TiO}_{2} \mathrm{~S}$, $\mathrm{TiO}_{2} \mathrm{P}$, and $\mathrm{TiO}_{2} \mathrm{H}$ were developed to maintain comparable thickness through the series (Table 1).

The surfaces of the fabricated films were studied by FE-SEM (Figure 2). At $\times 10 \mathrm{~K}$ magnification, no microdefects, such as holes, cracks or peeling of the $\mathrm{TiO}_{2}$ film from the surface of $\mathrm{Pt} / \mathrm{Ti} / \mathrm{SiO}_{2}$ were observed in all cases (Figure 2a-c). We recall that images at higher magnifications of a semiconductor surface of $\mathrm{TiO}_{2} \mathrm{P}$, already reported in literature, reveal nanocrystallites' presence on the surface $[18,19]$. Meanwhile, a previously published FE-SEM image of $\mathrm{TiO}_{2} \mathrm{~S}$ [16] displayed a smooth homogeneous surface with nanocrystallites. A higher magnification image $(\times 30 \mathrm{~K})$ of a $\mathrm{TiO}_{2} \mathrm{H}$ semiconductor layer confirms that the sample's pristine surface is covered with crystallites of $\mathrm{TiO}_{2}$ (Figure 2d). Homogeneous brightness on adjacent areas, about a few hundred nanometers wide, are likely produced by different surface angles facing the detector in a chamber or by different crystallite orientations.

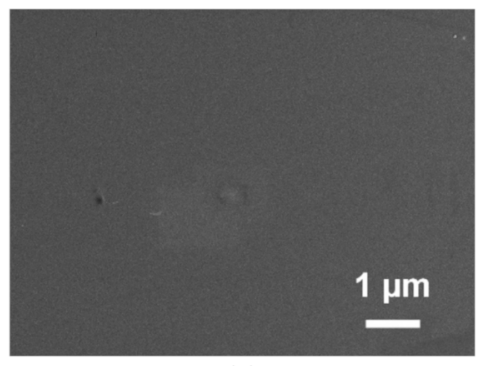

(a)

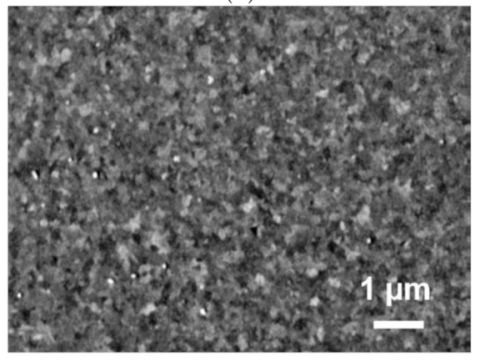

(c)

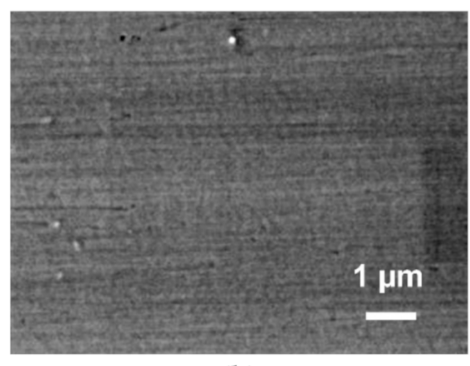

(b)

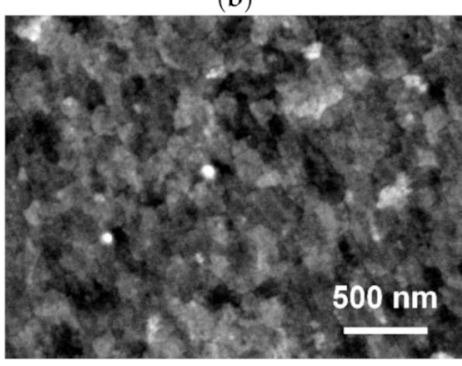

(d)

Figure 2. FE-SEM images of semiconductor layers in $\mathrm{TiO}_{2} \mathrm{P}(\mathbf{a}), \mathrm{TiO}_{2} \mathrm{~S}(\mathbf{b})$ and $\mathrm{TiO}_{2} \mathrm{H}(\mathbf{c}$,d). Magnification is $\times 10 \mathrm{~K}(\mathbf{a}-\mathbf{c})$ and $\times 30 \mathrm{~K}(\mathbf{d})$, with corresponding length bars of $1 \mu \mathrm{m}$ and $500 \mathrm{~nm}$. 
We previously studied the chemical properties of $\mathrm{TiO}_{2} \mathrm{~S}$ and $\mathrm{TiO}_{2} \mathrm{P}[18-20,23]$. Thus, we analyzed only the $\mathrm{TiO}_{2} \mathrm{H}$ surface by XPS. Figure 3 a shows a wide range spectrum, evidencing the presence of O1s, Ti2p, and C1s core levels. Ti2p feature is composed of a 3/2-1/2 doublet, located at 458.56 and $464.30 \mathrm{eV}$ (Figure 3b), the typical BEs of $\mathrm{TiO}_{2}[18-20,23]$. No other components are present, suggesting the absence of other types of titanium oxides. O1s core level (Figure 3c) is characterized by the main peak at $529.83 \mathrm{eV}$, related to oxygen in $\mathrm{TiO}_{2}$, and a second feature at $531.37 \mathrm{eV}$, due to $\mathrm{CO}$ groups in agreement with the presence of the $\mathrm{C} 1$ s core level. The energy difference between Ti2p $3 / 2$ peak and O1s component related to Ti-O bond is $5.72 \mathrm{eV}$, while the $\mathrm{O} / \mathrm{Ti}$ stoichiometry ratio is 2.03. All data are in good agreement with the expected values for $\mathrm{TiO}_{2}$ [24].
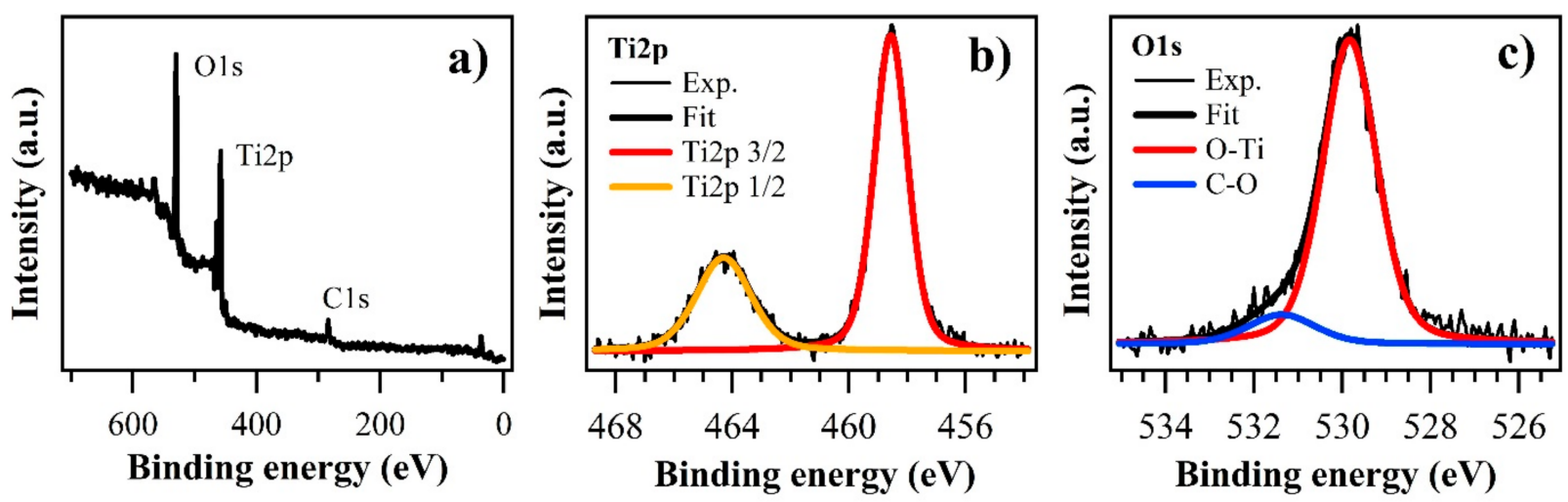

Figure 3. XPS analysis of $\mathrm{TiO}_{2} \mathrm{H}$ surface. Wide range spectrum (a), Ti2p (b) and O1s (c) core levels are shown, with details about peak components.

Concerning analysis of electrical properties, as the metal oxide's initial resistance is typically higher than $10^{10} \Omega$, a voltage-controlled electroforming procedure is applied to observe the resistance switching behavior. The electroforming is performed by applying to a TE (grounding the BE) a sweep voltage from 0 to $-10 \mathrm{~V}$ (with a current compliance of $0.5 \mathrm{~mA}$, to avoid a hard dielectric breakdown), where the conductive filament is produced, then from -10 to $0 \mathrm{~V}$ and from 0 to $+1.5 \mathrm{~V}$ (with a current compliance of $100 \mathrm{~mA}$ ) and then back to $0 \mathrm{~V}[23,25]$, to break the new filament. The performance of the devices varies greatly depending on the voltage/current parameters used for forming the conducting filament $[7,26]$. Therefore, we decided to apply an identical electroforming procedure for all $\mathrm{TiO}_{2}$ based devices to ensure the memristive response's reproducibility. The I-V curves (shown in Figures 4-6) were obtained by sweeping the activated devices in a low resistance state. At first, upon the negative voltage sweep, the activated devices reach $\mathrm{V}_{\mathrm{OFF}}$, at which the material switches from a low to a high resistance state, then a sweep to positive voltage values is applied until $V_{O N}$ is reached, at which a high to a low resistance state switch occurs. Finally, by turning back to $0 \mathrm{~V}$, we complete the hysteresis loop with a $(\mathrm{V}, \mathrm{I})=(0,0)$ pinch. The compliance current is set to $0.5 \mathrm{~mA}$, the sweep rate is set to $0.02 \mathrm{Vs}^{-1}$. In all electrical studies, the first consecutive hysteresis cycles are shown, and all $\mathrm{R}_{\mathrm{ON}}$ (resistance in the high conductivity state) and $\mathrm{R}_{\mathrm{OFF}}$ (resistance in the low conductivity state) values are measured at $0.1 \mathrm{~V}$. No significant physical deformation of the TE structure was observed for any the devices. 

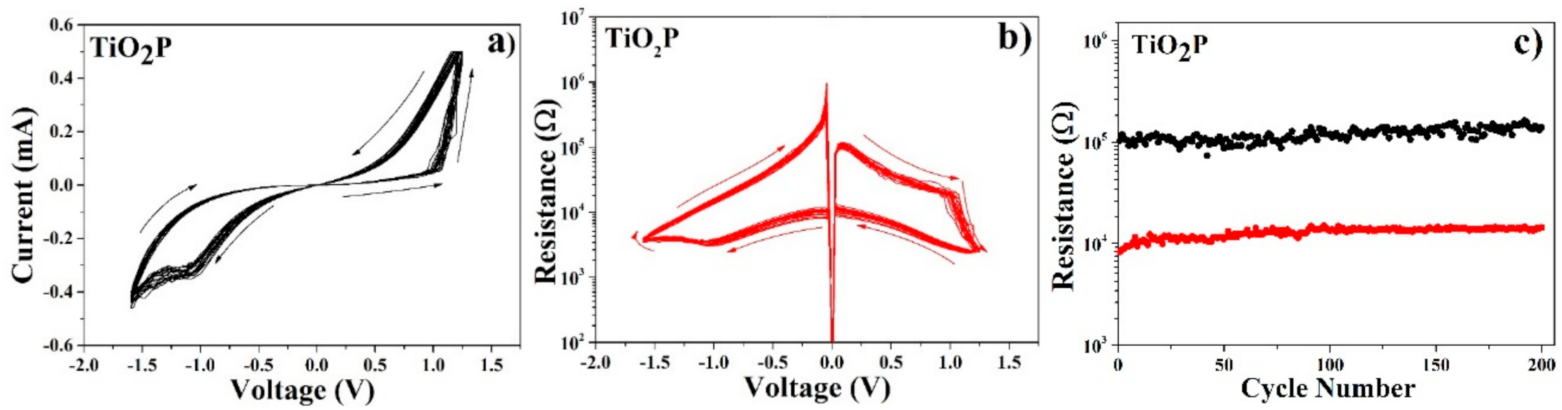

Figure 4. Typical electrical characteristics of $\mathrm{TiO}_{2} \mathrm{P}$ device, having Pt discs as a top electrode. I-V (a), $\mathrm{R}-\mathrm{V}$ (b) curves together with device life (c; $\mathrm{R}_{\mathrm{OFF}}$ black dots, $\mathrm{R}_{\mathrm{ON}}$ red dots).
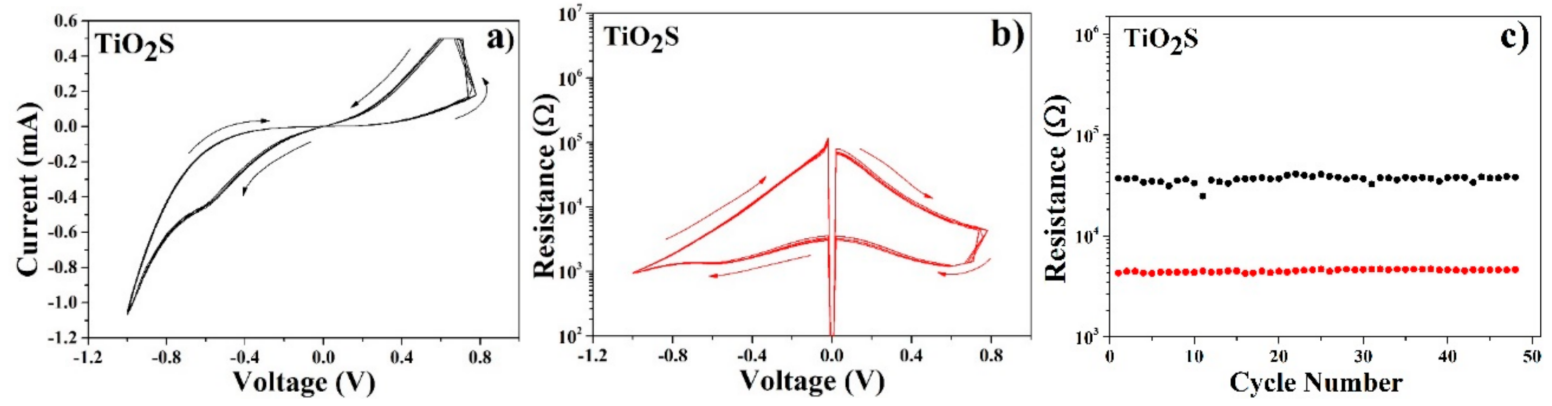

Figure 5. Typical electrical characteristics of $\mathrm{TiO}_{2} \mathrm{~S}$ device, having Pt discs as a top electrode. I-V (a), $\mathrm{R}-\mathrm{V}$ (b) curves together with device life (c; $\mathrm{R}_{\mathrm{OFF}}$ black dots, $\mathrm{R}_{\mathrm{ON}}$ red dots).
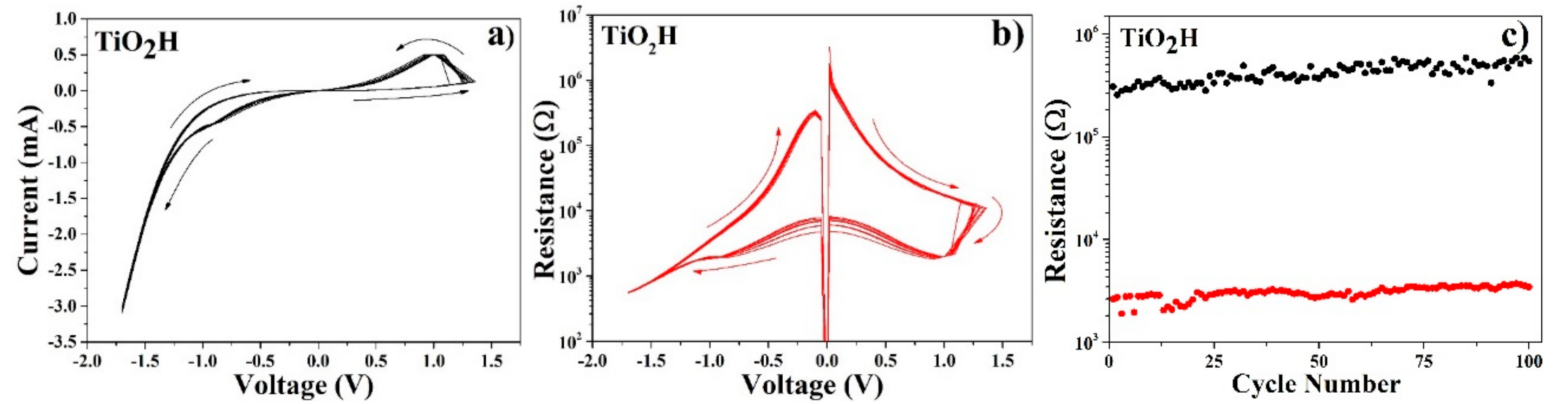

Figure 6. Typical electrical characteristics of $\mathrm{TiO}_{2} \mathrm{H}$ device, having Pt discs as a top electrode. I-V (a), $\mathrm{R}-\mathrm{V}$ (b) curves together with device life (c; $\mathrm{R}_{\mathrm{OFF}}$ black dots, $\mathrm{R}_{\mathrm{ON}}$ red dots).

Figure 4 shows 20 typical I-V (a) and R-V (b) curves for the $\mathrm{TiO}_{2} \mathrm{P}$ film. $\mathrm{V}_{\mathrm{ON}}$ value is about $1.00 \pm 0.10 \mathrm{~V}$, while $\mathrm{V}_{\mathrm{OFF}}$ is about $-1.00 \pm 0.10 \mathrm{~V}$. Resistance in the low and high conductivity states are about $10^{5}$ and $10^{4} \Omega$, respectively, with a $\mathrm{R}_{\mathrm{OFF}} / \mathrm{R}_{\mathrm{ON}}$ ratio of about 10. The typical percentage of circular TE showing shorts with the BE is about $90 \pm 2 \%$. Nevertheless, device life is typically higher than 200 cycles (Figure 4c).

Figure 5 shows hysteresis loops acquired for the $\mathrm{TiO}_{2} \mathrm{~S}$ devices (I-V (a), $\mathrm{R}-\mathrm{V}$ (b) curves). $\mathrm{V}_{\mathrm{ON}}$ and $\mathrm{V}_{\mathrm{OFF}}$ are at about $0.75 \pm 0.10 \mathrm{~V}$ and $-0.62 \pm 0.10 \mathrm{~V}$, correspondingly, $\mathrm{R}_{\mathrm{OFF}}$ and $R_{\mathrm{ON}}$ values are about $5 \times 10^{4}$ and $5 \times 10^{3} \Omega$, with a $R_{\mathrm{OFF}} / \mathrm{R}_{\mathrm{ON}}$ ratio of about 10 . The percentage of the devices showing shorts is about $5 \pm 2 \%$, with most of the devices exceeding 50 cycles (Figure $5 \mathrm{c}$ ).

In Figure 6, I-V (a) and $\mathrm{R}-\mathrm{V}$ (b) curves for the $\mathrm{TiO}_{2} \mathrm{H}$ devices are shown. $\mathrm{V}_{\mathrm{ON}}$ is at $1.27 \pm 0.10 \mathrm{~V}, \mathrm{~V}_{\mathrm{OFF}}$ is at $-0.90 \pm 0.10 \mathrm{~V}$. Resistance values for $\mathrm{R}_{\mathrm{OFF}}$ and $\mathrm{R}_{\mathrm{ON}}$ are about $4 \times 10^{5}$ and $3 \times 10^{3} \Omega$, correspondingly, with a $\mathrm{R}_{\mathrm{OFF}} / \mathrm{R}_{\mathrm{ON}}$ ratio higher than 100 . The percentage of the devices with TE-BE shorts is about $40 \pm 2 \%$, while a typical device life exceeds 100 cycles (Figure 6c). The key resistive switching parameters are summarized in Table 2. 
Table 2. The resistive switching parameters for all devices.

\begin{tabular}{cccc}
\hline Parameter & $\mathbf{T i O}_{2} \mathbf{P}$ & $\mathbf{T i O}_{2} \mathbf{H}$ & $\mathbf{T i O}_{2} \mathbf{S}$ \\
\hline $\mathrm{V}_{\mathrm{ON}}$ & $1.00 \pm 0.10 \mathrm{~V}$ & $1.27 \pm 0.10 \mathrm{~V}$ & $0.75 \pm 0.10 \mathrm{~V}$ \\
\hline $\mathrm{V}_{\mathrm{OFF}}$ & $-1.00 \pm 0.10 \mathrm{~V}$ & $-0.90 \pm 0.10 \mathrm{~V}$ & $-0.62 \pm 0.10 \mathrm{~V}$ \\
\hline $\mathrm{R}_{\mathrm{ON}}$ & $10^{4} \Omega$ & $3 \times 10^{3} \Omega$ & $5 \times 10^{3} \Omega$ \\
\hline $\mathrm{R}_{\mathrm{OFF}}$ & $10^{5} \Omega$ & $4 \times 10^{5} \Omega$ & $5 \times 10^{4} \Omega$ \\
\hline $\mathrm{R}_{\mathrm{OFF}} / \mathrm{R}_{\mathrm{ON}}$ & 10 & $>100$ & 10 \\
\hline Short circuit devices & $90 \pm 2 \%$ & $40 \pm 2 \%$ & $5 \pm 2 \%$ \\
\hline $\begin{array}{c}\text { Number of resistive } \\
\text { switching cycles }\end{array}$ & $\geq 200$ & $\geq 100$ & $\geq 50$ \\
\hline
\end{tabular}

\section{Discussion}

Chemical and structural properties of the $\mathrm{TiO}_{2}$ films in $\mathrm{TiO}_{2} \mathrm{P}$ and $\mathrm{TiO}_{2} \mathrm{~S}$ devices have already been extensively studied $[5,16,18,19,23]$, both showing anatase crystal structure with aggregates of tens and hundreds of nanometers, respectively, while $\mathrm{TiO}_{2} \mathrm{P}$ is characterized by high porosity. $\mathrm{TiO}_{2}$ in $\mathrm{TiO}_{2} \mathrm{H}$ shows a surface structure and a roughness similar to the metal oxide film in $\mathrm{TiO}_{2} \mathrm{~S}$, suggesting that at least from a morphological point of view, the underlying $\mathrm{TiO}_{2} \mathrm{P}$ film does not influence the sol-gel topmost layer morphology significantly. Conversely, it is difficult to identify the effect of processing thermal treatments on the underlying $\mathrm{PMCS}^{\mathrm{TiO}}{ }_{2}$ film. The controlled deposition of nanometric aggregates with a highly defined ordered structure achievable by PMCS at room temperature is one of this technique's main advantages, as demonstrated for different materials and growth parameters [27-29]. Post-deposition thermal annealing at $450{ }^{\circ} \mathrm{C}$ in vacuum was reported for $\mathrm{PMCS} \mathrm{TiO}_{2}$ [19], with the source working parameters optimized for gas sensing, i.e., with very high porosity [18]. Even though these conditions differ from the one used in this work, the nanocrystallites previously described in literature did not show any change in structure and dimension upon the thermal treatment, but only a slight loss of oxygen due to the annealing in vacuum. This should not occur in $\mathrm{TiO}_{2} \mathrm{H}$ where annealing is performed in air. Thus, we can assume that the properties observed for $\mathrm{TiO}_{2} \mathrm{P}$ are preserved in the $\mathrm{TiO}_{2}$ layer developed by the PMCS in $\mathrm{TiO}_{2} \mathrm{H}$.

$\mathrm{TiO}_{2} \mathrm{H}$ surface has stoichiometric titanium dioxide chemical properties, with no oxygen defects and absence of other oxides fingerprints. XPS data agree with those of $\mathrm{TiO}_{2} \mathrm{~S}$ [24], being XPS, a technique with high surface sensitivity and sampled depth of about $4-8 \mathrm{~nm}$ for this material, i.e., the topmost $\mathrm{TiO}_{2}$ layer realized by sol-gel. This confirms we achieved high reproducibility and control of the sol-gel approach.

The electrical properties of $\mathrm{TiO}_{2} \mathrm{~S}$ are very similar to already published results, even though in a different crossbar architecture [23], suggesting satisfactory repeatability of the sol-gel approach for the development of the devices. Concerning $\mathrm{TiO}_{2} \mathrm{P}$, all main parameters ( $\mathrm{V}_{\mathrm{ON}}, \mathrm{V}_{\mathrm{OFF}}, \mathrm{R}_{\mathrm{ON}}$ and $\left.\mathrm{R}_{\mathrm{OFF}}\right)$ have slightly higher values than in previously published works [25]. This is attributed to the different $\mathrm{TiO}_{2}$ synthesis parameters since in the previously published data, a pure Helium transport gas instead of the $0.1 \%$ oxygen gas mixture applied in this work. Moreover, in the previous studies, all resistive switching loops were measured using a Pt wire. In this work, Pt dishes were used as a TE. The electrical properties of all studied devices are summarized in Table 2. The memristive performance of the $\mathrm{TiO}_{2} \mathrm{~S}$ device differs from the $\mathrm{TiO}_{2} \mathrm{P}$ one. The $\mathrm{TiO}_{2} \mathrm{~S}$ shows lower switching voltages and ON-OFF resistances, lower durability, and a considerably lower probability of short circuits of the devices than $\mathrm{TiO}_{2} \mathrm{P}$. However, $\mathrm{R}_{\mathrm{OFF}} / \mathrm{R}_{\mathrm{ON}}$ ratio is the same. Since the film thickness, chemical, and structural properties are very similar in the two model devices, the observed differences in electrical performance are probably due to the intrinsic nanostructure as observed in $\mathrm{TiO}_{2}$ [1] and other materials [30]. Likewise, the high percentage of devices with electrical shorts in the $\mathrm{TiO}_{2} \mathrm{P}$ set has the same origin, i.e., the higher porosity of the $\mathrm{TiO}_{2}$ layer compared to the sol-gel derived metal oxide. 
The number and size of grain borders in the PMCS films favors an efficient Pt percolation from the TE to the BE inside the film, upon the deposition of the topmost electrode. A more detailed understanding of the different electrical characteristics of the three types of devices, even though quite interesting, would require a more detailed analysis and modeling of the memristive mechanism that goes beyond the scope of this study.

The acquired hysteresis loops (Figures $4 \mathrm{a}, 5 \mathrm{a}$ and $6 \mathrm{a}$ ) are bipolar and $(\mathrm{V}, \mathrm{I})=(0,0)$ pinched; thus, we can classify all the devices as a generic memristor [31], with only $\mathrm{TiO}_{2} \mathrm{P}$ showing a symmetrical shape. It is important to note that the device produced by the hybrid method, $\mathrm{TiO}_{2} \mathrm{H}$, displays memristive switching properties after electroforming by analogy with the two models. Therefore, the hybrid deposition method combining the PMCS and the sol-gel techniques for forming the metal oxide layer is a new versatile tool for developing memristive devices.

The detailed insight into the $\mathrm{TiO}_{2} \mathrm{H}$ electrical performances shows that $\mathrm{V}_{\mathrm{ON}}$ and $\mathrm{V}_{\mathrm{OFF}}$ resemble $\mathrm{TiO}_{2} \mathrm{P}$ rather than those of $\mathrm{TiO}_{2} \mathrm{~S}$. $\mathrm{R}_{\mathrm{ON}}$ in $\mathrm{TiO}_{2} \mathrm{H}$ devices is lower than in both model devices. Conversely, $\mathrm{TiO}_{2} \mathrm{H}$ has higher resistance in the insulating state, an effect that could be due to the formation of a complex interface between the two metal oxide layers, characterized by different morphology and structure. The percentage of the $\mathrm{TiO}_{2} \mathrm{H}$ working devices is significantly higher than for PMCS-derived $\mathrm{TiO}_{2} \mathrm{P}$; thus, the topmost sol-gel derived $\mathrm{TiO}_{2}$ layer's deposition was beneficial for preventing the presence of short circuits related to the porosity of the titanium dioxide layer in $\mathrm{TiO}_{2} \mathrm{P}$ (Table 2). The loop's highly asymmetric shape can probably be converted to a more symmetrical one by an electroforming procedure that should be optimized for the hybrid structure $[7,26]$. However, we did not consider modifying the electroforming step to make the comparison of the devices based on three different processes more understandable and fairer. The $\mathrm{TiO}_{2} \mathrm{H}$ device life cycle is higher than for $\mathrm{TiO}_{2} \mathrm{~S}$, and $\mathrm{R}_{\mathrm{OFF}} / \mathrm{R}_{\mathrm{ON}}$ ratio is one order of magnitude higher than the two model devices. Considering all $\mathrm{TiO}_{2} \mathrm{H}$ device electrical features is difficult to identify the switching position in the layer. e.g., close to the BE or TE. However, there is a clear role of the interface between the PMCS and sol-gel derived layers. We conclude that the interface leads to higher/lower resistances in non conducting/conducting states, respectively, with significant improvement of $\mathrm{R}_{\mathrm{OFF}} / \mathrm{R}_{\mathrm{ON}}$, one of the main parameters defining memristive switching quality.

From the properties discussed above and the comparison of the performances of the three different memristive devices studied, we believe in having proved to be able to combine and exploit the best properties achievable independently by the PMCS and sol-gel methods compensating their specific weaknesses. Hence, the proposed HM approach is well suited to fabricate memristive devices with improved performances.

\section{Conclusions}

This paper successfully proposes and demonstrates the hybrid deposition method for developing the $\mathrm{TiO}_{2}$ films combining PMCS and sol-gel, two established techniques for metal oxides synthesis in vacuum and wet chemistry, respectively. While these two methods independently produce $\mathrm{TiO}_{2}$ films showing satisfactory memristive properties, their specific morphological and structural characteristics lead to drawbacks that can affect the overall device performances. We showed that these weaknesses can be strengthened or overcome by developing a novel hybrid method merging the sol-gel and the PMCS techniques. We analyzed the approach's performances in detail, comparing the PMCS $\left(\mathrm{TiO}_{2} \mathrm{P}\right)$ and the sol-gel $\left(\mathrm{TiO}_{2} \mathrm{~S}\right)$ derived devices to the hybrid $\mathrm{TiO}_{2} \mathrm{H}$, where the PMCS film was deposited on the $\mathrm{BE}$, and the sol-gel $\mathrm{TiO}_{2}$ was deposited on the top of it. The new material shows typical memristive switching, a reduced percentage of electrical shorts to $\mathrm{TiO}_{2} \mathrm{P}$, and higher life cycles than $\mathrm{TiO}_{2} \mathrm{~S}$, benefitting from both techniques and showing a reliable approach for memristive electronic devices.

Additionally, we found that $\mathrm{TiO}_{2} \mathrm{H}$ gives a $\mathrm{R}_{\mathrm{OFF}} / \mathrm{R}_{\mathrm{ON}}$, the most crucial parameter for a memristor, one order of magnitude higher than that for both the PMCS and sol-gel techniques used independently. Since the PMCS growth method precisely controls the 
composition of $\mathrm{TiO}_{2}$, tuning the oxygen atomic percentage from under to over stoichiometry while giving a fine control of the film thickness, its use paves the way to create interfaces between titanium oxides with a range of vacancies distribution. This represents a novel strategy for modulating the position of the switching zone in the conducting filament. Moreover, based on the achieved results, we envisage the perspective of developing stacked structures of different oxides thanks to the versatility of both the PMCS and the sol-gel methods. The functionalization of the bottom film with organic molecules that can dope the interface with charge donors, acceptors, could further tune the material's memristive properties.

Author Contributions: Conceptualization, V.P., G.G., and R.V.; methodology, V.P. and G.G.; validation, R.V. and S.D.; formal analysis, all authors; investigation, all authors; resources, L.L., S.I., and S.D.; writing—original draft preparation, V.P. and R.V.; writing—review and editing, V.P. and R.V.; supervision, R.V., S.I., and S.D.; project administration, L.L., S.I., and S.D. All authors have read and agreed to the published version of the manuscript.

Funding: This work was supported by the MaDEleNA project in the framework of the "Grandi Progetti 2012" funded by Autonomous Province of Trento, Italy (PAT) (319393-S116/2013): “Developing and studying novel intelligent nano materials and devices towards adaptive electronics and neuroscience applications".

Institutional Review Board Statement: Not applicable.

Informed Consent Statement: Not applicable.

Data Availability Statement: All data in this work are available on request by contact with the corresponding author.

Acknowledgments: We acknowledge C. Corradi and M. Pola for their valuable technical support.

Conflicts of Interest: The authors declare no conflict of interest.

\section{References}

1. Yang, J.J.; Pickett, M.D.; Li, X.; Ohlberg, D.A.A.; Stewart, D.R.; Williams, R.S. Memristive switching mechanism for metal/oxide/metal nanodevices. Nat. Nanotechnol. 2008, 3, 429-433. [CrossRef] [PubMed]

2. Gale, E. $\mathrm{TiO}_{2}$-based memristors and ReRAM: Materials, mechanisms and models (a review). Semicond. Sci. Technol. $2014,29$. [CrossRef]

3. Hu, S.; Liu, Y.; Liu, Z.; Chen, T.; Wang, J.; Yu, Q.; Deng, L.; Yin, Y.; Hosaka, S. Associative memory realized by a reconfigurable memristive Hopfield neural network. Nat. Commun. 2015, 6, 7522. [CrossRef] [PubMed]

4. Chang, W.-Y.; Lai, Y.-C.; Wu, T.-B.; Wang, S.-F.; Chen, F.; Tsai, M.-J. Unipolar resistive switching characteristics of ZnO thin films for nonvolatile memory applications. Appl. Phys. Lett. 2008, 92, 022110. [CrossRef]

5. Prusakova, V.; Collini, C.; Lunelli, L.; Vanzetti, L.; Chiappini, A.; Lorenzelli, L.; Pederzolli, C.; Chiasera, A.; Ferrari, M.; Dire', S. Towards low voltage resistive switch in sol-gel derived $\mathrm{TiO}_{2} / \mathrm{Ta}_{2} \mathrm{O}_{5}$ stack thin films. Mater. Des. 2016, 105, 359-365. [CrossRef]

6. Strukov, D.B.; Snider, G.S.; Stewart, D.R.; Williams, R.S. The missing memristor found. Nature 2008, 453, 80-83. [CrossRef]

7. Ielmini, D. Resistive switching memories based on metal oxides: Mechanisms, reliability and scaling. Semicond. Sci. Technol. 2016, 31, 063002. [CrossRef]

8. Paris, A.; Taioli, S. Multiscale investigation of oxygen vacancies in $\mathrm{TiO}_{2}$ anatase and their role in Memristor's Behavior. J. Phys. Chem. C 2016, 120, 22045-22053. [CrossRef]

9. Ascoli, A.; Tetzlaff, R.; Biolek, Z.; Kolka, Z.; Biolkova, V.; Biolek, D. The art of finding accurate Memristor Model solutions. IEEE J. Emerg. Sel. Top. Circuits Syst. 2015, 5, 133-142. [CrossRef]

10. Choi, B.J.; Jeong, D.S.; Kim, S.K.; Rohde, C.; Choi, S.; Oh, J.H.; Kim, H.J.; Hwang, C.S.; Szot, K.; Waser, R.; et al. Resistive switching mechanism of $\mathrm{TiO}_{2}$ thin films grown by atomic-layer deposition. J. Appl. Phys. 2005, 98, 033715. [CrossRef]

11. Baldi, G.; Bosi, M.; Giusti, G.; Attolini, G.; Berzina, T.; Collini, C.; Lorenzelli, L.; Mosca, R.; Nozar, P.; Ponraj, J.S.; et al. Optimization of synthesis protocols to control the nanostructure and the morphology of metal oxide thin films for memristive applications. AIP Conf. Proc. 2015, 1648, 280002. [CrossRef]

12. Rafieian, D.; Ogieglo, W.; Savenije, T.; Lammertink, R.G.H. Controlled formation of anatase and rutile $\mathrm{TiO}_{2}$ thin films by reactive magnetron sputtering. AIP Adv. 2015, 5, 097168. [CrossRef]

13. Albertinetti, N.; Minden, H.T. Granularity in ion-beam-sputtered $\mathrm{TiO}_{2}$ films. Appl. Opt. 1996, 35, 5620-5625. [CrossRef] [PubMed]

14. Kamarozaman, N.S.; Aznilinda, Z.; Herman, S.H.; Bakar, R.A.; Rusop, M. Effect of annealing duration on the memristive behavior of $\mathrm{Pt} / \mathrm{TiO}_{2} / \mathrm{ITO}$ memristive device. In Proceedings of the 2012 10th IEEE International Conference on Semiconductor Electronics (ICSE), Kuala Lumpur, Malaysia, 19-21 September 2012; Volume 2, pp. 703-706. [CrossRef] 
15. Peñaloza-Mendoza, Y.; Ponce-Cabrera, L. Comparison on morphological and optical properties of $\mathrm{TiO}_{2}$ thin films grown by single-pulse and multi-pulse laser ablation. J. Surf. Eng. Mater. Adv. Technol. 2015, 5, 17-23. [CrossRef]

16. Prusakova, V.; Armellini, C.; Carpentiero, A.; Chiappini, A.; Collini, C.; Dirè, S.; Ferrari, M.; Lorenzelli, L.; Nardello, M.; Normani, S.; et al. Morphologic, structural, and optical characterization of sol-gel derived $\mathrm{TiO}_{2}$ thin films for memristive devices. Phys. Status Solidi C 2014, 12, 192-196. [CrossRef]

17. Simanjuntak, F.M.; Panda, D.; Wei, K.-H.; Tseng, T.-Y. Status and prospects of ZnO-based resistive switching memory devices. Nanoscale Res. Lett. 2016, 11, 1-31. [CrossRef] [PubMed]

18. Toccoli, T.; Capone, S.; Guerini, L.; Anderle, M.; Boschetti, A.; Iacob, E.; Micheli, V.; Siciliano, P.A.; Iannotta, S. Growth of titanium dioxide films by cluster supersonic beams for VOC sensing applications. IEEE Sens. J. 2003, 3, 199-205. [CrossRef]

19. Detto, F.; Armani, N.; Lazzarini, L.; Toccoli, T.; Verucchi, R.; Aversa, L.; Nardi, M.V.; Rossi, B.; Salviati, G.; Iannotta, S. Excitonic recombination in superstoichiometric nanocrystalline $\mathrm{TiO}_{2}$ grown by cluster precursors at room temperature. Phys. Chem. Chem. Phys. 2012, 14, 5705-5710. [CrossRef]

20. Roncador, A.; Jimenez-Garduño, A.M.; Pasquardini, L.; Giusti, G.; Cornella, N.; Lunelli, L.; Potrich, C.; Bartali, R.; Aversa, L.;

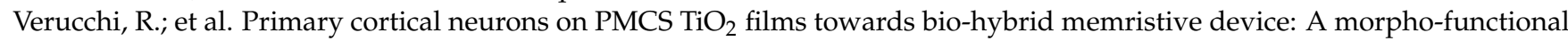
study. Biophys. Chem. 2017, 229, 115-122. [CrossRef]

21. Taurino, A.M.; Capone, S.; Boschetti, A.; Toccoli, T.; Verucchi, R.; Pallaoro, A.; Siciliano, P.A.; Iannotta, S. Titanium dioxide thin films prepared by seeded supersonic beams for gas sensing applications. Sens. Actuators B Chem. 2004, 100, 177-184. [CrossRef]

22. Nardi, M.; Verucchi, R.; Aversa, L.; Casarin, M.; Vittadini, A.; Mahne, N.; Giglia, A.; Nannarone, S.; Iannotta, S. Electronic properties of tetrakis (pentafluorophenyl)porphyrin. New J. Chem. 2013, 37, 1036-1045. [CrossRef]

23. Prusakova, V.; Collini, C.; Nardi, M.; Tatti, R.; Lunelli, L.; Vanzetti, L.; Lorenzelli, L.; Baldi, G.; Chiappini, A.; Chiasera, A.; et al. The development of sol-gel derived $\mathrm{TiO}_{2}$ thin films and corresponding memristor architectures. RSC Adv. 2017, 7, 1654-1663. [CrossRef]

24. Biesinger, M.C.; Lau, L.W.; Gerson, A.R.; Smart, R.S. Resolving surface chemical states in XPS analysis of first row transition metals, oxides and hydroxides: Sc, Ti, V, Cu and Zn. Appl. Surf. Sci. 2010, 257, 887-898. [CrossRef]

25. Lunelli, L.; Collini, C.; Jimenez-Garduño, A.; Roncador, A.; Giusti, G.; Verucchi, R.; Pasquardini, L.; Iannotta, S.; Macchi, P.; Lorenzelli, L.; et al. Prototyping a memristive-based device to analyze neuronal excitability. Biophys. Chem. 2019, $253,106212$. [CrossRef] [PubMed]

26. Kim, K.M.; Kim, G.H.; Song, S.J.; Seok, J.Y.; Lee, M.H.; Yoon, J.H.; Hwang, C.S. Electrically configurable electroforming and bipolar resistive switching in $\mathrm{Pt} / \mathrm{TiO}_{2} / \mathrm{Pt}$ structures. Nanotechnology 2010, 21, 305203. [CrossRef] [PubMed]

27. Barborini, E.; Piseri, P.; Milani, P. A pulsed microplasma source of high intensity supersonic carbon cluster beams. J. Phys. D Appl. Phys. 1999, 32, L105-L109. [CrossRef]

28. Barborini, E.; Piseri, P.; Mutti, S.; Milani, P.; Biasioli, F.; Iannotta, S.; Gialanella, S. Synthesis of nanocrystalline TiNi thin films by cluster beam deposition. Nanostruct. Mater. 1998, 10, 1023-1031. [CrossRef]

29. Barborini, E.; Piseri, P.; Bassi, A.L.; Ferrari, A.; Bottani, C.; Milani, P. Synthesis of carbon films with controlled nanostructure by separation of neutral clusters in supersonic beams. Chem. Phys. Lett. 1999, 300, 633-638. [CrossRef]

30. Sangwan, V.K.; Jariwala, D.; Kim, I.S.; Chen, K.-S.; Marks, T.J.; Lauhon, L.J.; Hersam, M.C. Gate-tunable memristive phenomena mediated by grain boundaries in single-layer MoS2. Nat. Nanotechnol. 2015, 10, 403-406. [CrossRef]

31. Chua, L. If it's pinched it's a memristor. Semicond. Sci. Technol. 2014, 29. [CrossRef] 